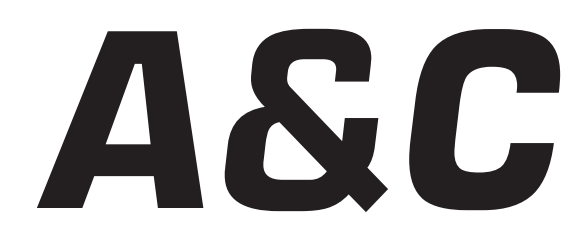

Revista de Direito Administrativo \& Constitucional

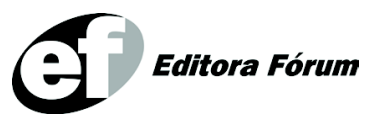

ISSN 1516-3210 


\section{A\&C REVISTA DE DIREITO ADMINISTRATIVO E CONSTITUCIONAL}

IPDA

Instituto Paranaense

de Direito Administrativo

Direção Geral

Romeu Felipe Bacellar Filho

Direção Editorial

Paulo Roberto Ferreira Motta

Direção Executiva

Emerson Gabardo

Conselho de Redação

Edgar Chiuratto Guimarães

Adriana da Costa Ricardo Schier

Célio Heitor Guimarães

\section{Conselho Editorial}

Adilson Abreu Dallari

Alice Gonzáles Borges

Carlos Ari Sundfeld

Carlos Ayres Britto

Carlos Delpiazzo

Cármen Lúcia Antunes Rocha

Celso Antônio Bandeira de Mello

Clèmerson Merlin Clève

Clóvis Beznos

Enrique Silva Cimma

Eros Roberto Grau

Fabrício Motta

Guilhermo Andrés Muñoz (in memoriam)

Jaime Rodríguez-Arana Muñoz

Jorge Luís Salomoni

José Carlos Abraão
José Eduardo Martins Cardoso
José Luís Said
José Mario Serrate Paz
Juan Pablo Cajarville Peruffo
Juarez Freitas
Julio Rodolfo Comadira
Luís Enrique Chase Plate
Lúcia Valle Figueiredo
Manoel de Oliveira Franco Sobrinho
(in memoriam)
Marçal Justen Filho
Marcelo Figueiredo
Márcio Cammarosano
Maria Cristina Cesar de Oliveira

Nelson Figueiredo

Odilon Borges Junior

Pascual Caiella

Paulo Eduardo Garrido Modesto

Paulo Henrique Blasi

Paulo Neves de Carvalho (in memoriam)

Paulo Ricardo Schier

Pedro Paulo de Almeida Dutra

Regina Maria Macedo Nery Ferrari

Rogério Gesta Leal

Rolando Pantoja Bauzá

Sérgio Ferraz

Valmir Pontes Filho

Yara Stropa

Weida Zancaner

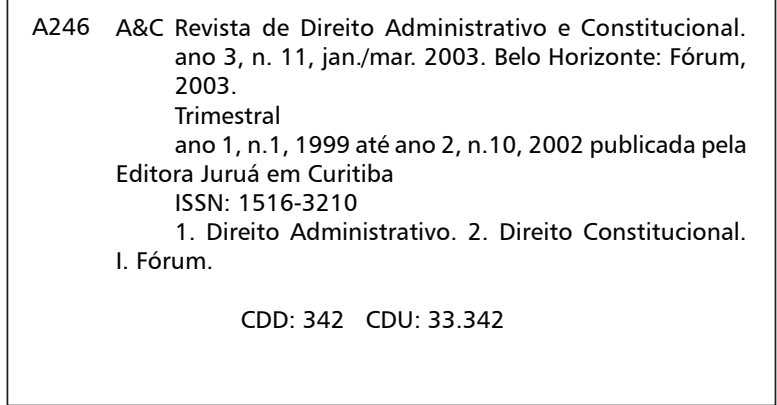

(C) Editora Fórum Ltda. 2007

Todos os direitos reservados. É proibida a reprodução total ou parcial, de qualquer forma ou por qualquer meio eletrônico ou mecânico, inclusive através de processos xerográficos, de fotocópias ou de gravação, sem permissão por escrito do possuidor dos direitos de cópias (Lei nº 9.610, de 19.02.1998).

Editora Fórum Ltda

Av. Afonso Pena, 2770 - 15\%16ª andar - Funcionários

CEP 30130-007 - Belo Horizonte/MG - Brasil

Tel.: 08007043737

Internet: www.editoraforum.com.br

e-mail: editoraforum@editoraforum.com.br
Editor responsável: Luís Cláudio Rodrigues Ferreira Projeto gráfico e diagramação: Luis Alberto Pimenta Revisora: Olga M. A. Sousa

Pesquisa jurídica: Fátima Ribeiro - OAB/MG 74868

Bibliotecária: Alessandra Rodrigues da Silva CRB 2778/MG 6 ${ }^{\text {a Região }}$

Os conceitos e opiniões expressas nos trabalhos assinados são de responsabilidade exclusiva de seus autores.

Impressa no Brasil / Printed in Brazil

Distribuída em todo Território Nacional 


\title{
"Conselho de Transparência Pública e Combate à Corrupção": inovações ao Decreto $\mathrm{n}^{\circ}$ 6.075, de 03.04.07
}

\author{
Francisco de Salles Almeida Mafra Filho* \\ Doutor em Direito Administrativo pela UFMG. Professor Adjunto da UFMT. Advogado em \\ Mato Grosso.
}

Palavras-chave: Transparência pública. Combate à corrupção. Controle da atuação do Estado.

Sumário: Introdução - Art. $1^{\circ}$ - Caput do artigo $3^{\circ}$ do Decreto $\mathrm{n}^{\circ} 4.923$ - Inciso I - Alíneas "g" e "h" - Inciso II - Inciso III - Alínea "f" - Alínea "g" - Representantes dos trabalhadores - Alínea "h" - Representantes dos empregadores - Alínea “i” - Alínea “j” - O $\S 2^{\circ}$ do artigo $3^{\circ}$ do Decreto no 4.923 - O $\S 5^{\circ}$ do artigo $3^{\circ}$ do Decreto $n^{\circ} 4.923-\mathrm{O} \S 6^{\circ}$ do artigo $3^{\circ}$ do Decreto $\mathrm{n}^{\circ} 4.923-\mathrm{O} \S 7^{\circ}$ do artigo $3^{\circ}$ do Decreto ${ }^{\circ} 4.923$ - Art. $5^{\circ}$ do Decreto $n^{\circ} 4.923$ - Conclusões

\section{Introdução}

O Decreto do Executivo $\mathrm{n}^{\mathrm{O}}$ 6.075, de 03 de abril de 2007, tem a referenda da Controladoria Geral da União e foi publicado na Seção 1 do Diário Oficial da União do dia seguinte, ou seja, 04 de abril de 2007, quarta-feira, na página 3 .

O tema central do Decreto $n^{\circ} 6.075$ é a alteração de normas que tratam do Conselho de Transparência Pública e Combate à Corrupção.

O Presidente da República, utilizando de sua competência privativa de sancionar, promulgar e fazer publicar as leis, bem como expedir decretos e regulamentos para sua fiel execução e de dispor, mediante decreto, sobre a organização e o funcionamento da administração federal, quando não implicar aumento de despesa nem criação ou extinção de órgãos públicos, e levando em consideração a competência e a composição da Controladoria Geral da União, decreta nova redação ao Decreto no 4.923, de 2003.

O Decreto $\mathrm{n}^{\mathrm{O}} 4923$, de 18 de dezembro de 2003 determina a natureza, finalidade, competência, composição, administração e prazo para a elaboração do Regimento Interno do Conselho de Transparência Pública e Combate à Corrupção.

É importante destacar que o artigo $17, \S 2^{\circ}$ da Lei $\mathrm{n}^{\circ} 10.683$, de 28 de maio de 2003 já previa que o Conselho de Transparência Pública e Combate à Corrupção seria composto paritariamente por representantes

*<kikomafra@gmail.com>; <f-mafra@uol.com.br>. 
da sociedade civil organizada e representantes do Governo Federal.

Art. $1^{\circ}$

$\mathrm{O}$ artigo $1^{\circ}$ do Decreto $\mathrm{n}^{\mathrm{o}} 6.075$ determina as novas redações que terão o artigo $3^{\circ}$ e o artigo $5^{\circ}$ do Decreto $n^{\circ} 4.923$, de 2003.

\section{Caput do artigo $3^{\circ}$ do Decreto $n^{\circ} 4.923$}

Em relação ao Decreto $\mathrm{n}^{\mathrm{o}} 4.923$, o caput do seu artigo $3^{\circ}$ determinava originalmente a composição do Conselho de Transparência Pública e Combate à Corrupção feita por dezoito conselheiros, designados pelo Presidente da República.

A primeira modificação sofrida no caput deste artigo ocorreu em função da edição do Decreto $n^{\circ}$ 5.187, de 18 de agosto de 2004. Este novo decreto aumentou de 18 para 20 o número de conselheiros a serem indicados pelo Presidente da República.

A modificação determinada pelo Decreto $\mathrm{n}^{\circ} 6.075$ prevê que, além dos vinte conselheiros, o Presidente da República também designará mais vinte suplentes para cada conselheiro.

É de se observar o aumento de $100 \%$ do número de pessoal que irá compor o Conselho.

\section{Inciso I}

$\mathrm{O}$ inciso I do artigo $3^{\circ}$ do Decreto $\mathrm{n}^{\mathrm{o}} 4.923$ determina que os conselheiros e seus suplentes devem ser escolhidos entre as autoridades do Poder Executivo Federal as seguintes: a) o Ministro de Estado do Controle e da Transparência; b) um representante da Casa Civil da Presidência da República; c) um representante da Advocacia-Geral da União; d) um representante do Ministério da Justiça; e) um representante do Ministério da Fazenda; f) um representante do Ministério do Planejamento, Orçamento e Gestão.

\section{Alíneas "g" e " $h$ "}

O texto original do inciso previa no item "g" a escolha de um representante da Comissão de Ética Pública da Presidência da República. O Decreto $\mathrm{n}^{\circ} 5.187$, de 2004 alterou esta previsão para a de um representante do Ministério das Relações Exteriores. Ao fazer isto, o mesmo Decreto acrescentou à redação original do inciso uma alínea "h" para

A \& C R. de Dir. Administrativo e Constitucional, Belo Horizonte, ano 7, n. 28, p. 77-82, abr./jun. 2007 
continuar prevendo a presença de um representante da Comissão de Ética Pública da Presidência da República.

Inciso II

O inciso II prevê que devem estar entre as autoridades públicas convidadas um representante do Ministério Público da União e um representante do Tribunal de Contas da União.

\section{Inciso III}

O inciso III prevê que, entre os representantes convidados da sociedade civil, devem estar presentes: a) um representante da Ordem dos Advogados do Brasil - OAB; b) um representante da Associação Brasileira de Imprensa; c) um representante da Transparência Brasil; d) um representante da Associação Brasileira de Organizações Não-Governamentais - ONG's; e) um representante da Conferência Nacional dos Bispos do Brasil - CNBB.

\section{Alínea "f"}

A redação anterior da alínea " $f$ " previa a existência de um representante do Conselho Nacional dos Pastores do Brasil.

O Decreto $n^{\circ} 5.043$, de 8 de abril de 2004 alterou a redação da alínea " $\mathrm{f}$ " para a que prevê a existência no Conselho de um representante indicado pelas igrejas evangélicas de âmbito nacional, organizadas segundo suas convenções, concílios gerais ou sínodos.

\section{Alínea " $g$ " - Representantes dos trabalhadores}

A alínea "g" determina a existência de um representante dos trabalhadores, indicado, em regime de alternância, por uma das seguintes entidades: 1. Central Única dos Trabalhadores; 2. Confederação Geral dos Trabalhadores; 3. Força Sindical; 4. Social-Democracia Sindical; 5. Confederação Nacional dos Trabalhadores da Agricultura.

\section{Alínea " $\mathrm{h}$ " - Representantes dos empregadores}

A alínea "h" prevê que deve compor o Conselho um representante dos empregadores, indicado, em regime de alternância, por uma das seguintes entidades: 1. Confederação Nacional da Agricultura; 2. Confederação Nacional do Comércio; 3. Confederação Nacional da Indústria; 4.

A \& C R. de Dir. Administrativo e Constitucional, Belo Horizonte, ano 7, n. 28, p. 77-82, abr./jun. 2007 
Confederação Nacional das Instituições Financeiras; 5. Confederação Nacional do Transporte;

Alínea "i"

A alínea "j" determina que também deve compor o Conselho um cidadão brasileiro que exerça atividade acadêmica, científica, cultural ou artística, escolhido entre pessoas de idoneidade moral e reputação ilibada, cuja atuação seja notória na área de competência do Conselho.

Alínea "j"

Finalmente, a alínea "j" prevê, desde que foi publicado o Decreto $\mathrm{n}^{\circ} 5.187$, em 19 de agosto de 2004, a existência de um representante do Instituto Ethos de Empresas e Responsabilidade Social.

\section{O $\S 2^{\circ}$ do artigo $3^{\circ}$ do Decreto $n^{\circ} 4.923$}

$\mathrm{O}$ artigo $3^{\circ}$, $\S 2^{\circ}$ do Decreto $\mathrm{n}^{\circ} 4.923$, de 18 de dezembro de 2003, previa que o Conselho de Transparência Pública e Combate à Corrupção contaria com uma Secretaria-Executiva, exercida pelo Subcontrolador-Geral da União.

A nova redação deste dispositivo determina simplesmente que o Conselho de Transparência Pública e Combate à Corrupção contará com uma Secretaria-Executiva, exercida pelo Secretário-Executivo da Controladoria-Geral da União.

O que ocorreu aqui foi a substituição do Subcontrolador-Geral da União pelo Secretário-Executivo da Controladoria-Geral da União.

Examinando-se o organograma da Controladoria Geral da União constata-se que o Secretário-Executivo da Controladoria-Geral da União está diretamente subordinado ao Ministro de Estado do Controle e da Transparência, titular daquela pasta.

Também é possível se detectar na internet que o atual Ministro da Controladoria Geral da União já exerceu o cargo de Subcontrolador-Geral da União.

Finalmente, é também possível se detectar que o SubcontroladorGeral da União, por exercício de lógica e por não constar nenhum outro cargo com esta denominação do organograma da CGU é, na verdade, o Secretário-Executivo da Controladoria-Geral da União.

A Lei $n^{\circ} 10.683$, de 28 de maio de 2003 trata da organização da

A \& C R. de Dir. Administrativo e Constitucional, Belo Horizonte, ano 7, n. 28, p. 77-82, abr./jun. 2007 
Presidência da República sofreu variadas modificações. Entretanto, nos artigos 17 a 20 pode-se ler o que prevê a mesma no tocante à Controladoria Geral da União (CGU).

Órgão integrante da Presidência da República, a CGU assiste direta e imediatamente o Presidente da República na defesa do patrimônio público, no controle interno, na auditoria pública, na correição, na prevenção e no combate à corrupção, nas atividades de ouvidoria e no aumento da transparência da gestão na administração pública federal.

\section{$0 \S 5^{\circ}$ do artigo $3^{\circ}$ do Decreto $n^{\circ} 4.923$}

O $\S 5^{\circ}$ do artigo $3^{\circ}$ do Decreto $n^{\circ} 4.923$ determinava que a critério do Presidente do Conselho de Transparência Pública e Combate à Corrupção, poderiam ser especialmente convidados a participar das reuniões do colegiado, sem direito a voto, titulares de outros órgãos ou entidades públicas, bem como organizações e pessoas que representassem a sociedade civil, sempre que da pauta constassem assuntos de sua área de atuação.

A nova redação do mesmo parágrafo simplesmente dispõe que os conselheiros suplentes exercerão a representação nas hipóteses de ausência ou impedimento dos respectivos titulares, e os sucederão, no caso de vacância.

\section{O $6^{\circ}$ do artigo $3^{\circ}$ do Decreto $n^{\circ} 4.923$}

A antiga redação do dispositivo do Decreto dispunha que a participação no Conselho de Transparência Pública e Combate à Corrupção era considerada serviço público relevante não remunerado.

A redação atual do mesmo $\S 6^{\circ}$ do Decreto $n^{\circ} 4.933$ dispõe que a critério do Presidente do Conselho de Transparência Pública e Combate à Corrupção, poderão ser especialmente convidados a participar das reuniões do colegiado, sem direito a voto, titulares de outros órgãos ou entidades públicas, bem como organizações e pessoas que representem a sociedade civil, sempre que da pauta constarem assuntos de sua área de atuação.

É fácil constatar-se a troca da antiga redação do $\S 5^{\circ}$ para o $\S 6^{\circ}$. A título de curiosidade, entretanto, deve ser ressaltado que o texto é exatamente o mesmo.

\section{O $\S 7^{\circ}$ do artigo $3^{\circ}$ do Decreto $n^{\circ} 4.923$}


A participação no Conselho de Transparência Pública e Combate à Corrupção continua sendo considerada serviço público relevante não remunerado, só que agora em um parágrafo $7^{\circ}$ que foi acrescentado ao texto original do Decreto $\mathrm{n}^{\mathrm{o}} 4.923$.

\section{Art. $5^{\circ}$ do Decreto $n^{\circ} 4.923$}

A modificação produzida no artigo $5^{\circ}$ do Decreto $\mathrm{n}^{\mathrm{o}} 4.923$ pelo Decreto $\mathrm{n}^{\circ} 6.075$ só confirma os comentários realizados acima acerca do significado semelhante de Subcontrolador-Geral da União e de SecretárioExecutivo da Controladoria-Geral da União.

Tudo isto porque doravante o "Conselho de Transparência Pública e Combate à Corrupção" vai receber o suporte administrativo e técnico da Secretaria-Executiva da Controladoria-Geral da União e não mais da Subcontroladoria Geral da União.

\section{Conclusões}

O combate à corrupção sempre foi e será um dos principais objetivos de todos os governos sérios. A corrupção é um mal que assola não só o Brasil, mas nações do mundo inteiro. Todas as medidas que contribuam para a diminuição dos graus de corrupção na sociedade brasileira devem ser aplaudidas. Entretanto, não se pode esquecer que é no ser humano, no indivíduo que exerce função, que se encontra a raiz de todos os males e a solução para todos os problemas da Administração Pública brasileira.

Informação bibliográfica deste texto, conforme a NBR 6023:2002 da Associação Brasileira de Normas Técnicas (ABNT):

MAFRA FILHO, Francisco de Salles Almeida. "Conselho de Transparência Pública e Combate à Corrupção": inovações ao Decreto no 6.075, de 03.04.07. A\&C Revista de Direito Administrativo e Constitucional, Belo Horizonte, ano 7, n. 28, p. 77-82, abr./jun. 2007 